From the Department of Child Health, Medical School

University of Indonesia, JaJcarta

\title{
Syndrome of Hyperviscosity in the Neonate (Literature Review).
}

by

\section{A,S. ONGKIE}

\section{Introduction}

Sixteen years ago, Chaptal et al. (cited by Mackintosh and Walker, 1973) described 5 infants with dyspnea and convulsions atiributable to polycythemia. One year later, in 1959, Wood reported 2 polycythemic infants with dyspnea and convulsions attributable to polycythemia as welli and thenceforth attention was called to this disorder and numerous papers have subsequently been published on this subject.

Cases in the literature which dealt with polycythemia appeared as maternal-fetal transfusions (Michael and Mauer, 1961), intrauterine parabiotic syndrome (Naeye, 1963), neonatal respiratory distress associated with a high hematocrit (Danks and Stevens, 1964), cardiopulmonary effects of placental transfusion (Buckels and Usher, 1965) the intrauterine twin-to-twin transfusion syn- drome (Singh and Sethi, 1969) and many others. The first report on hyperviscosity in the neonate documented in the Indonesian literature was published by Sukadi and Alisjahbana (1974) while ours is stilli in manuscript.

Gross et al. (1973) defined polycythemia as a venous hematocrit of $65 \%$ or greater and it is now recognized that polycythemia may produce symptoms in the newborn. It was Baum in 1966 who first reported the existing relation between hematocrit and blood viscosity in the neonate.

Syndrome of hyperviscosity in the neonate deserves special attention of pediatricians in general and neonatologists in particular as newborn infants are particularly susceptible to developing hyperviscosity and treatment directed to lowering viscosity is promising. Clinical manifestations associated with hyperviscosity 
may not only result in permanent sequelae (Gross et al., 1973) but lifethreatening as well.

This paper tries to present a brief review on the many-sided problem of the syndrome of hyperviscosity in the neonate.

\section{Etiology}

Syndrome of hyperviscosity may arise from increased number of cells (polycythemia or leukemia), increased resistance of cells to deformation (sickle cell disease or hereditary spherocytosis), and elevated plasma viscosity. Increased concentrattion of fibrinogen or the macroglobulins, IgM or SF19, in the myelomatous process or Walldenstrom's macroglobuilinemia may increase plasma viscosity. Polycythemic hyperviscosity is the most common of all hyperviscosity conditions (Wells, 1970).

Neonatal polycythemia may be due to several factors.

1. Relative intrauterine anoxia may increase erythrocyte production (Walker and Turnbull, 1953) by increasing erythropoietin production (Chaptail et al., 1958 as cited by Gatty et al., 1966; Gross et a.l, 1973; Gersony, 1973). However, Mackintosh and Walker (1973) suggested that maternal hypoxia and fetal asphyxia at birth increase the blood catecholamines in their respective circulations, assumed to cause more vasoconstriction of the umbilical artery than of the vein, encoura- ging transfer of blood from placenta to fetus. Mackintosh and Walker (1973) cited Philíp et al., (1969) as stating that the hypoxic induction of uterine contractions encourages transfer of blood from placenta to fetus.

2. Small for gestational age and postmaturity.

Humbert et al. (1969) reporting on polycythemia in small for gestational age infants attributed to possible chronic hypoxia in utero. Six of the 18 Gross' (1973) polycythemic infants were small for gestational age. Most of Baum's (1967) sixteen hyperviscous newborns showed evidences of dysmaturity (cited by Schaffer and Avery, 1971). Fetal hypoxia is often associated with placental insufficiency.

3. Chromosomal abnormalities (Weinberger and Oleinick, 1970; Kontras, 1972; Lappalainen and Kouvalainen, 1972).

In newborn infants with Down's syndrome there is evidence that a myeloproliferative disorder of the bone marrow contributes to polycythemia.

4. Maternofetal transfusion and twin-to-twin transfusion in identical twins (Michael and Mauer, 1961; Naeye, 1963; Singh and Sethi, 1969). Naeye (1963) demonstrated the presence of arteriovenous fistulas in the placenta. The diagnosis of maternofetal 
transfusion is based on (Gatti et al., 1966) :

a. High hematocrit and hemoglobulin values.

b. A low proportion of fetal hemoglobulin.

c. The demonstration of maternal erythrocytes in the infant's blood by differential agglutination which is most convincing.

d. The presence of Beta $_{2} \mathrm{~A}$-globulin (IgA) in the infant's serum.

In twin-to-twin transfusion there is severe anemia in one twin and intense pllethora in the other. This occurs only in monochorionic (uniovular) twins where vascular anastomosis between the two parts of the placenta has been found to be invariably present. The vascular shunts may be readily identified with milk or infant formula as the contrast media (Coen and Sutherland, 1970).

5. Delayed clamping of the cord. Infants whose cords are clamped Iate have langer blood volumes, higher hematocrits and altered hemodynamics when compared to infants whose cords are clamped early. Usher in 1963 demonstrated that about $40 \mathrm{ml}$ blood is transferred within 15 seconds and an average of $166 \mathrm{ml}$ within $5 \mathrm{mi}$ nutes after delivery, when the infant is held below the introitus and the cord left undisturbed. Buckels an Usher (1965) found that the capillary hematocrit at 4 hours of age laverages $56.4 \%$ after early (about 5 seconds after birth), and $75.1 \%$ after delayed (5 minutes after birth) cord clamping. These findings suggest that placental transfusion may play an jimportant role during the first minutes of life.

\section{Physiology and Pathophysiology}

A modified classification of polycythemia by Murray (1966) was put forward by Kontras (1972) as follows:

I. Relative polycythemia, hemoconcentration.

III. Primary polycythemia.

A. Polycythemia vera

B. Benign familial polycythemia or erythrocytosis.

III. Secondary polycythemia.

A. Insufficient oxygen delivery.

1. Low environmental $\mathrm{O}_{2}$ (high altitude)

2. Impaired ventilation-pulmonary disease, obesity

3. Cyanotic congenital heant disease

4. Abnormal hemoglobins

a. Methemoglobinemia (congenital, acquired)

b. Hemoglobin variants

B. Increases in erythrocyte-stimulating substances (Erythropoietin). 
1. Malignant tissue-renal, cerebellar lesions, hepatic, adrenal.

2. Benign lesions

3. Exogenous stimulation-chemical and physical agents

IV. Neonatal polycythemia.

In this respect we will only deal with the neonatal polycythemia.

Walker and Turnbull (1953) had shown that a fall in the oxygen supply to the fetus during intrauterine life does exert a profound influence on the production of erythrocytes and formation of hemoglobin. Normally, the hemoglobin level rises steadily from $9 \mathrm{gm} \%$ at the 10th week to 14-15 by the 22nd-24th week. From the 36th week there is a general tendency for the level to rise so that by the $40 \mathrm{th}$ week, the range is from 15 to $18.8 \mathrm{gm}$ and by the $43 \mathrm{rd}$ week the mean value is 18.8 $\mathrm{gm}$, the range being $16.8 \mathrm{gm}$ to 20.5 $\mathrm{gm}$. In case of prolonged pregnancy the rise is maintained (Fig. 1).

The erythrocyte count shows a similar paittern. The count rises steadily from $1,420,000$ at 10 weeks to $3,280,000$ at 25 weeks. From then till 36 weeks the increase is slow. From the 36ith week the spread out is in the same way as does the hemogilobin so that by the 40 th week the range is from $3,740,000$ to $4,940,000$ with a mean of $4,350,000$. After the 40th week the increase continues (Fig. 2).
During the first few hours after binth, an increase in erythrocyta count, hematocrit and hemoglobin takes place. Usher et al., (1963) explained it as partially resulting from a placental transfusion at the time of delivery with subsequent fluid shift decreasing the plasma volume (cited by Oski and Naiman, 1966).

Gross et al. (1973) proposed the following scheme for the etiology and pathogenesis of symptomatic hyperviscosity states in the neonate. (diagram 1).

Neonatal hyperviscosity is considered to be primarily influenced by erythrocyte number. Increased visco. sity causes sludging of flow resul. ting in impaired tissue oxygenation and consequent acidosis leading to decreased erythrocyte deformability. Tissue hypoxia of the brain, kidneys and lungs leads to clinical signs and symptoms. The high viscosity can aIter the cerebrospinal fluid secretion, circulation and absorption, and result in a further rise of intracranial pressure accounting for the eye changes frequently seen on funduscopical examination (Chrispin and Darke, 1962). Hypoglycemia is a frequently associated finding in polycy. themia but the causal relationship has not been olearly demonstrated yet. Hyperbilirubinemia may be related to premature destruction of erythrocytes in an abnormal circulation as evidenced by burred and fragmented cells often found in polycythemic 
FIG. 1 : Hemoglobin levels in cord blood of human fetus in normal pregnancy (Adapted from Walker \& Turnbull, 1953).

HEMOGLOBIN GM \%

$\%$
21

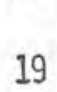

17

15

19

13

.11

9

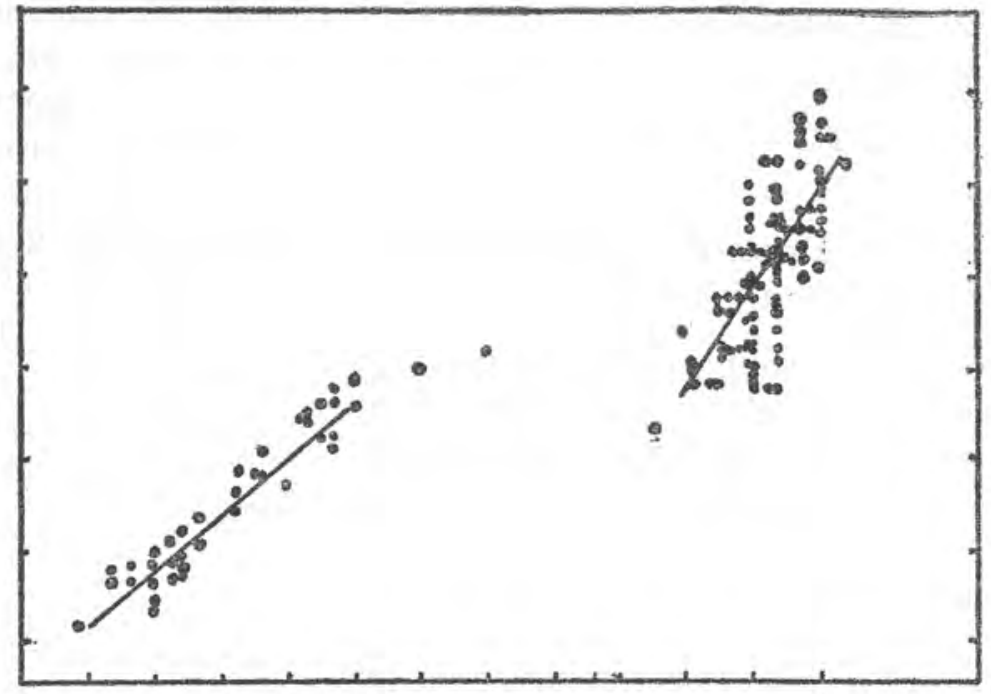

$\begin{array}{llllllllllll}10 & 13 & 16 & 19 & 22 & 25 & 28 & 31 & 34 & 37 & 40 & 43\end{array}$

MENSTRUAL AGE AT DELIVERY (WEEKS),

FIG. 2: Red cell cont in cord biood of humam fetus in normal pregnancy (Adapted from Waiker \& Turnbull, 1953).

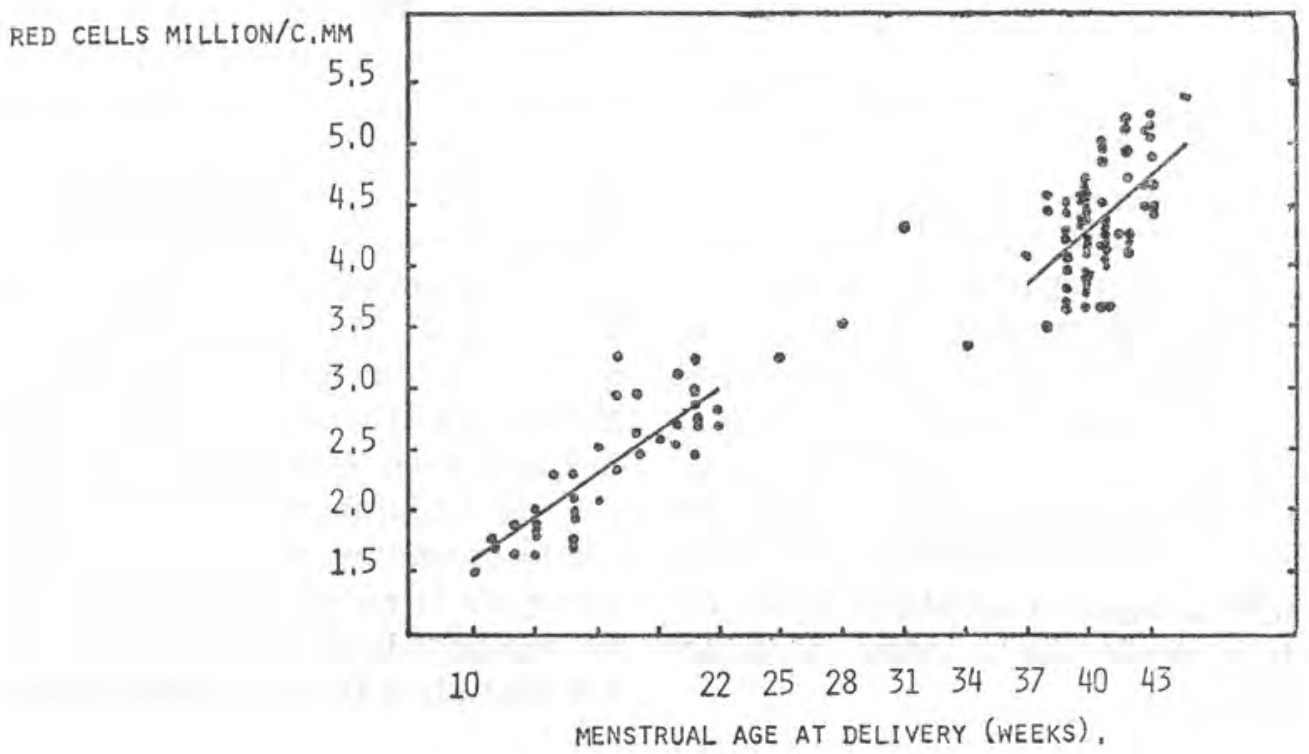


infants and carries the risk of kernicterus. Thrombocytopenia may be due to consumption of thrombocytes during sludging. Disseminated intravascular coagulation may be another complication of hyperviscosity (Kontras et al, 1970). Transfusion may result in circulatory overload which could be held responsible for the car. diomegaly frequently seen on the chest film, respiratory distress and plethora. The newborn erythrocytes are less deformable contributing to whole blood hyperviscosity.

Normovolemic polycythemia is found in infants who are dysmature or small for gestational age (Hum. bert et al., 1969). Murray et al., (1963), Replogle and Merrill (1970) and Fouron and Hebert (1973) had demonstrated that in normovolemic polycythemia there is a fall in the systemic cardiac output with increased hematocnit related to the higher viscosity and secondarily to the diminished venous return to the right heart. The pulmonary vascular resistance progressively increases with increasing hematocrit and at a hematocrit of about $70 \%$, a right-to-left shunt appears through the ductus arteriosus and foramen ovale creating a peripheral hypoxia which in turn increases the shunting by causing peripheral vasodilatation (Fouron and Hebert, 1973; Gersony, 1973). It should probably be regarded as the limit above which clinical symptoms could be anticipated (Mackintosh and
Walker, 1973). This value of hematocrit is furthermore a justification for therapeutic phlebotomy in hypervolemic polycythemia (Fouron and Hebert, 1973).

Gregg and Wiggers in 1933 (aited by Murray et al., 1963) had shown an increase in cardiac output in hypervolemic polycythemia (as in transfusion syndromes). Murray et al., (1963) showed that the cardiac output is significantly higher in hypervolemia than in normovolemia in all hematocrit ranges compared (Fig. 3).

Cardiac output has a significant inverse correlation to hematocrit in both normovolemic and hypervclemic polycythemia. Cardiac output is ap. proximately twice as high in hypervolemic as in normovolemic polycy. themia at any comparakle hematocr't.

However, whether or not the cardiac output is increased in hypervolemic polycythemia depends upon the hematocrit under consideration; for example, inspection of fig. 3 shows that cardiac output at a hypervolemic hematocrit of $60 \%$ is higher while cardiac output at a hypervole. mic hematocrit of $70 \%$ is lower than the cardiac output at a normovolemic hematocrit of $45 \%$. A decreased cardiac output with a consequent reduction in tissue blood flow leadis to peripheral hypoxia.Replogle and Merrill (1970) stated that the incre- 
DIAGRAM 1 : Pathogenesis of symptomatic hyperviscosity states in meonate.

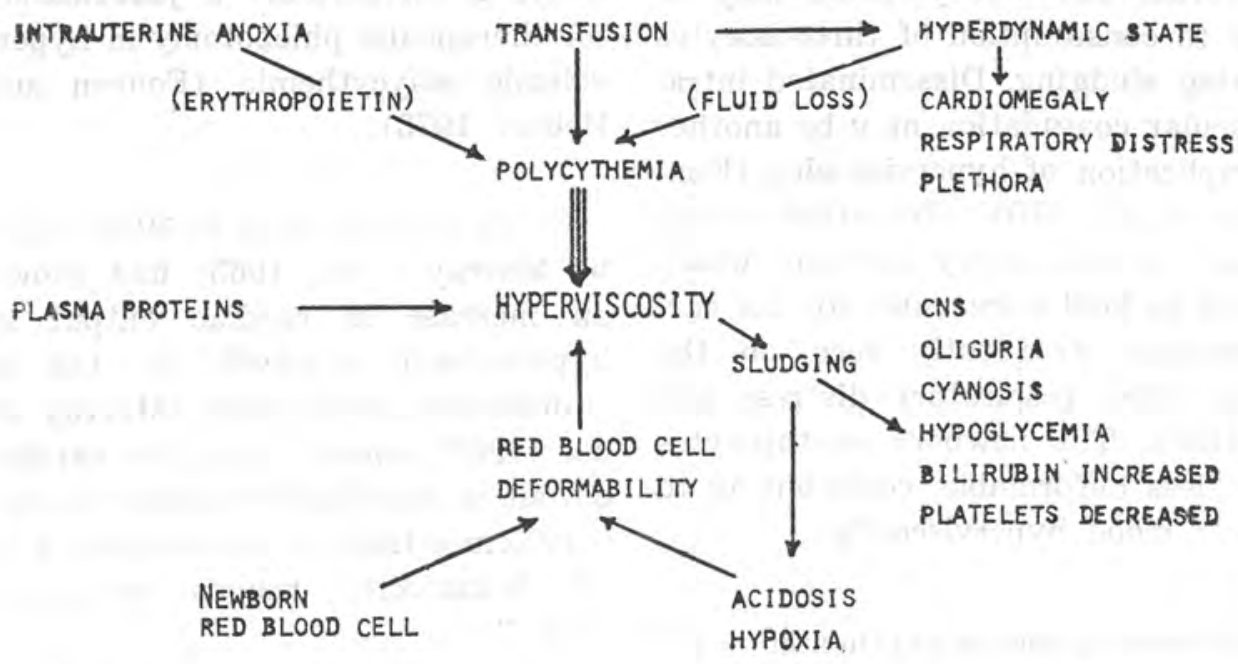

FIG. 3 : Cardiac output,hematocrit curve (Adapted from Murray et al., 1963)

CARDIAC OUTPUT

$M L, / K G, / M I N$,

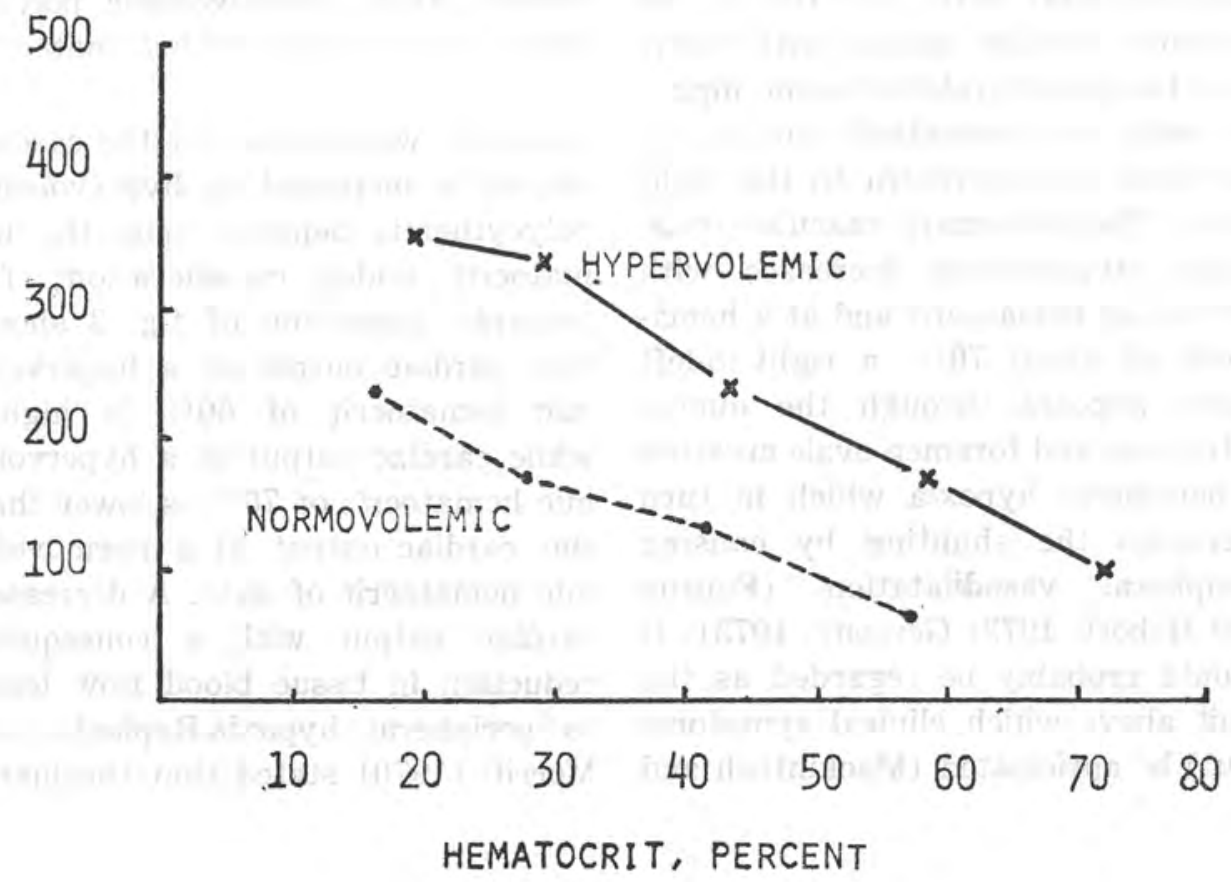


ased orygen carrying capacity of the erythrocyte-rich blood does not compensate for the reduced cardiac output associated with polycythemia.

\section{Viscosity-Hematocrit and Viscosity- Shear Rate Relations}

There is virtually a straight line relation between viscosity and hematocrit over the normal range, but at hematocrit values greater than $65 \%$ there is a progressively larger increase in viscosity for each unit change in hematocrit (Baum, 1966; Mackintosh and Walker, 1973) as illustrated in Fig. 4.

At high hematocrit levels minor increases in hematocrit produce marked increases in viscosity.

The viscosity of blood is not fixed but varies with the rate of shear (velocity gradient) and the dimension of the conducting vessel. At low rates of shear, there is a relatively higher viscosity value for a given hematocrit and the eurve approximates a linear function. At high shear rates, the curve moves down and to the right with lower values for viscosity at hematocrit levels comparable to those plotted at low rates of shear (Wells and Merril, 1961) as shown in Fig, 4.

The unit of viscosity is centipoise (ep) defined as (Skovborg et al. 1966). shear istress (dymes per sq. cm)

shear rate (inverse seconds)

Shear stress relates to the frictional forces within a fluid during flow. Wells and Merrill (1961) have estimated that the rate of shear in the aorta is 230.00 sec. $^{-1}$ and in small arterioles and venules $11.50 \mathrm{sec}^{-1}$.

At the low shear rates, which exist under certain physiological conditions, hyperviscosity could result in reduced blood flow in the microcirculation even to the extent of complete blood stasis as shown in Fig. 5 and Table 1.

\section{Clinical Manưfestations}

The infant usually appears plethoric, cyanotic, or both. The colour is somewhat more purplish than the usual cyanosis.

Cerebral signs include excessive irritability, stiffness, jitteriness, generalized or focal seizures or, conversely, severe lethargy, inability to suck, and marked hypotonia, associated at times with apnea and cyanosis (Wood, 1959; Kontras, 1972; Mackintosh and Walker, 1973; Gross et al., 1973).

Cardiopulmonary signs and symptoms like tachypnea, dyspnea with cardliac decompensation or spells of apnea (Naeye, 1963; Danks and Stevens, 1964; Gatti et al, 1966; O'Connor et al., 1968; Kontras, 1972; Gross et al., 1973; Fouron and Hebert, 1973). These signs and symp- 
FIS. 4: Viscosity/Hemaiocrit curves at difforent shear rates (Adapted from Weils \& Merrinl, 1961).

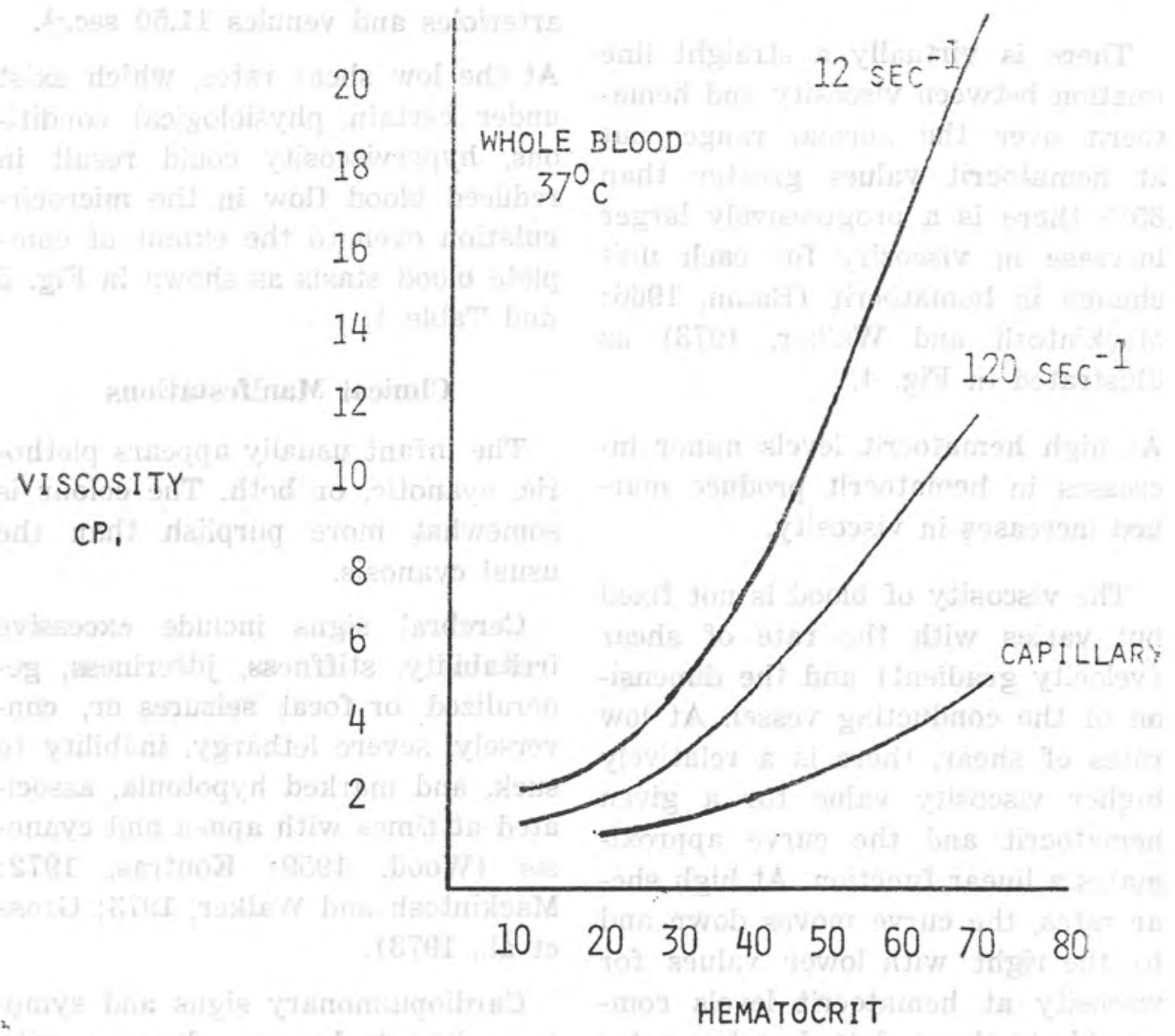


toms may lead one to establish an erraneous dilagnosis of cyanotic congenital heart disease. It is of additional interest and importance, however, that in Gatiti's experience patients under the age of 1 month with cyanotic heart disease rarely have hematocrit values over $65 \%$.

Fouron and Hebert (1973) believed that plethora with signs of cardiac failure are associated with polycythemic hypervolemia whereas cyanosis with cerebral signs and symptoms are associated with polycythemic normovolemila.

Papageargiou and Stern (1972) reported a case of a newborn infant with gangrene of the night index finger in which the only abnormal finding other than the gangrenous finger was the high hematocrit $(78 \%)$. They explained it as caused by hypoxia resulting from interferred red cell passage and tissue perfusion.

Humbert et all., (1969) described 2 male infants with priapism in whom polycythemia was the only detectable cause.

Signs and symptoms of hypoglycemia, increased bilirubin and coagulation defects may be noted because of sludging of blood fllow.

Gross et al., (1973) presented the following histogram of signs and symptoms associlated with hyperviscasity in 18 neonates (Figure 6).

Actually, the majonity of infants with abnormally high hematocrits do not develop clinical disease which is not readily explained from the reported studies. Gatti et al., (1966) found neither cyanosis nor cardiorespiratory distress in 25 infants with hematocrit values greater than $75 \%$.

Humbert et al., (1969) stated that: "centain groups of polycythemic infants seem more prone to develop associated complications than others" and found small for gestational age infants and male infants to be such groups. Fahey et al. (1965) suggested host factors which determine the vulnerability of individuals to elevated viscosiiy.

\section{Laboratory and other related examinations}

In some patients there may be roentgenographic evidence of cardiac enlargement and pulmonary vascular congestion with or without pleural fluid (Gatti et al, 1966; O'Connor et al, 1968; Lees, 1970). A simple chest roentgenogram can help to differentiate between polycythemia with hypervolemia and polycythemia without hypervolemia. In presence of hypervolemia and cardiac failure, cardiomegaly is a eonstant finding (Fouron and Hebert, 1973). However, the cardiovascular changes are transient and subside concurrently with the abnormal hematologic findings (Gatti et al., 1966). O'Connor et $a l,$. (1968) postulated that a portion or all of the blood normally distributed in the placenta is transfused 
FIG. 5 : Viscosity/ Shear nate curve (Adapted from Wells \& Merrill, 1961)..

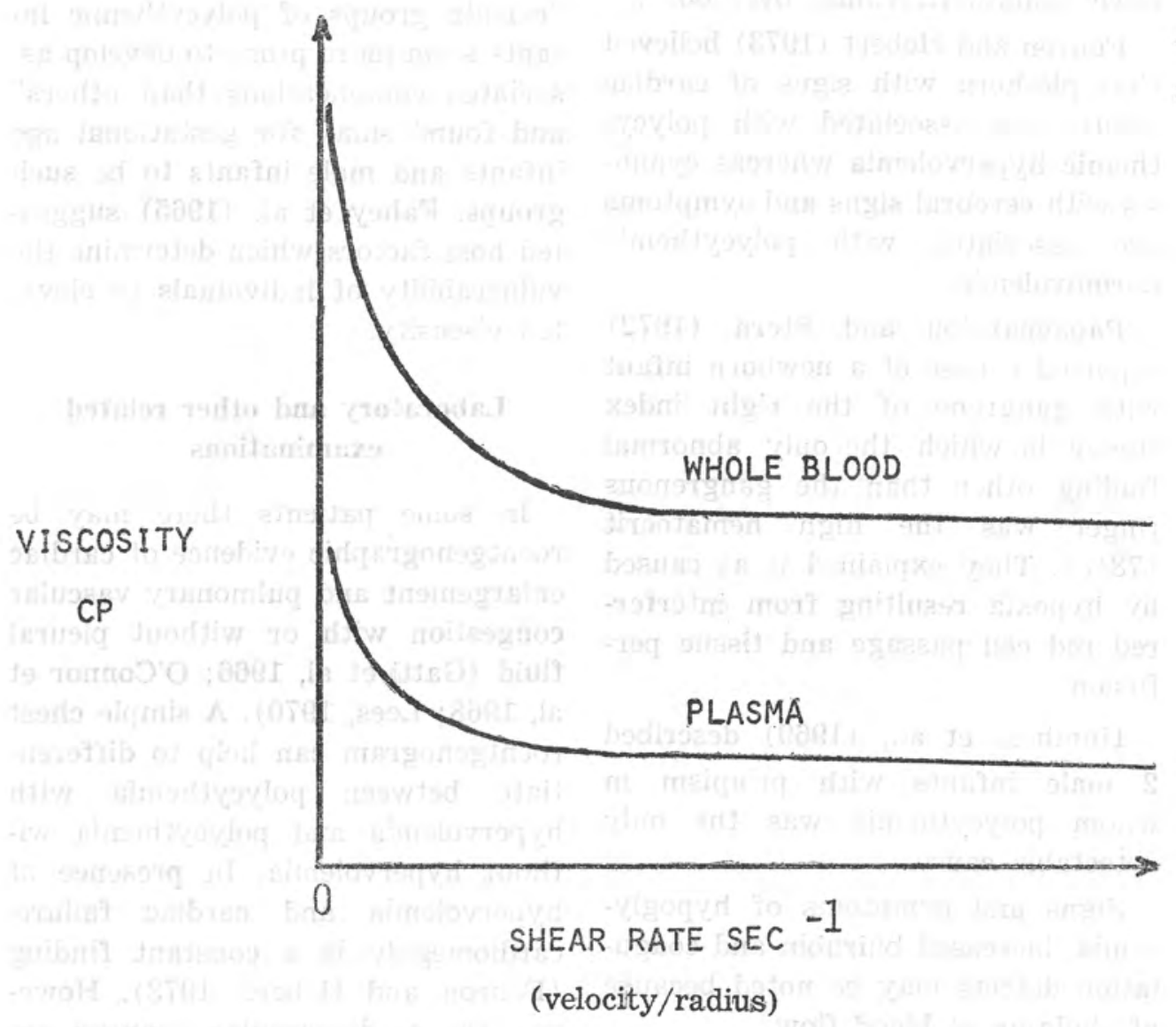


into the infant at some time in the perinatal period resulting in hypervolemia, pulmonary congestion, cardiomegaly due to congenital heart failure and pleural effusion. Possible micro-emboli or thrombosis in the pulmonary circulation causes pleural fluid, pulmonary vascular congestion and cardiomegaly.

An abnormal electrocardiogram may be found during the period of cardiorespiratory distress.

An abnormal electroencephalogram may be found with or without seizures (Gross et al., 1973).

Funduscopical findings may be that of papilloedema, retinal hemorrhage, dilatation and tortuosity of the retinal vessels or central retinal vein closures (Meadows, 1947; Ohrispin and Darke, 1962; Rothstein, 1972).

Guest and Brown in 1957 (cited by Kontras, 1972) recorded a mean cord blood hematocrit of $52.3 \%$. They found a hematocrit of $58.2 \%$ on day $1,54.5 \%$ on day 3 and $54.9 \%$ at 1 week. Moe (1965) reported normail capillary blood hemoglobin content, hematocnit level and erythrocyte count to be $19.8 \mathrm{gm} \%$ '(S.D. = $2.4), 65.9 \%$ (S.D. $=7.5)$ and 5.40 mill. $/ \mathrm{mm}^{3}$ (S.D. $=0.65$ ) respectively, from 2 to 6 days of age. Sommer and Kontras (1971), cited by Kontras (1972) studying venous blood found average hematocrits of $55 \%$ \pm 6.5 for day $1,51 \% \pm 5.91$ for day 2 , and $51 \% \pm 5.98$ for day 3 . The source of sampling is to be taken into consideration. The average erythrocyte count is 804,000 per cmi and the hemoglobin $2.85 \mathrm{gm} \%$ higher in the capillary samples (Wood, 1959) and this marked capillary venous hematocnit difference is observed during the first 5 days of life. Heel warming improves the capillary venous hematocrit correlation ( $\mathrm{Oh}$ and Lind, 1966).

The hematocrit can be determined by making use of a microhematocrit centrifuge.

Viscosity of heparinized (7 units per $\mathrm{ml}$ ) whole blood (1.2 $\mathrm{ml}$ sample) can be determined using a WellsBrookfield microviscometer with circulating water bath at $37^{\circ} \mathrm{C}$. This apparatus can measure the shear stress at 8 different shear rates $(230,115,46,23,11.5,5.75,2.3$ and $\left.1.15 \mathrm{sec}^{-1}\right)$. The shear stress developed in the blood can be read from a dial. The viscosity is calculated by dividing the measured shear stress by the corresponding shear rate (Skovborg et al,, 1966).

Filterability is a measure of erythrocyte deformability. Filterability of washed cells is measured as flow velocity (microlitres per second) during constant flow.

Considening the afore-mentioned pathophysiology, determination of blood unconjugated bilirubin, blood smear for signs of hemolysis, thrombocyte count and other coagulation studies pertinent to intravascular 
A.S. ONGKIE

TABLE 1 :Viscosity in the newborn (cp) (Mackintosh and Walker, 1973).

\begin{tabular}{rcc}
\hline $\begin{array}{c}\text { Shear rate } \\
\text { Sec-1 }\end{array}$ & Mean & 1 SD \\
\hline 1.16 & 33.7 & 9.5 \\
2.32 & 23.8 & 5.6 \\
5.70 & 15.0 & 3.2 \\
11.50 & 11.2 & 2.1 \\
23.00 & 9.0 & 1.6 \\
46.00 & 7.3 & 1.3 \\
116.00 & 6.0 & 1.0 \\
232.00 & 5.5 & 1.1 \\
\hline
\end{tabular}

FIG 6 : His ogram of signs and symptoms associated with hyperviscosity in 18 neonates.

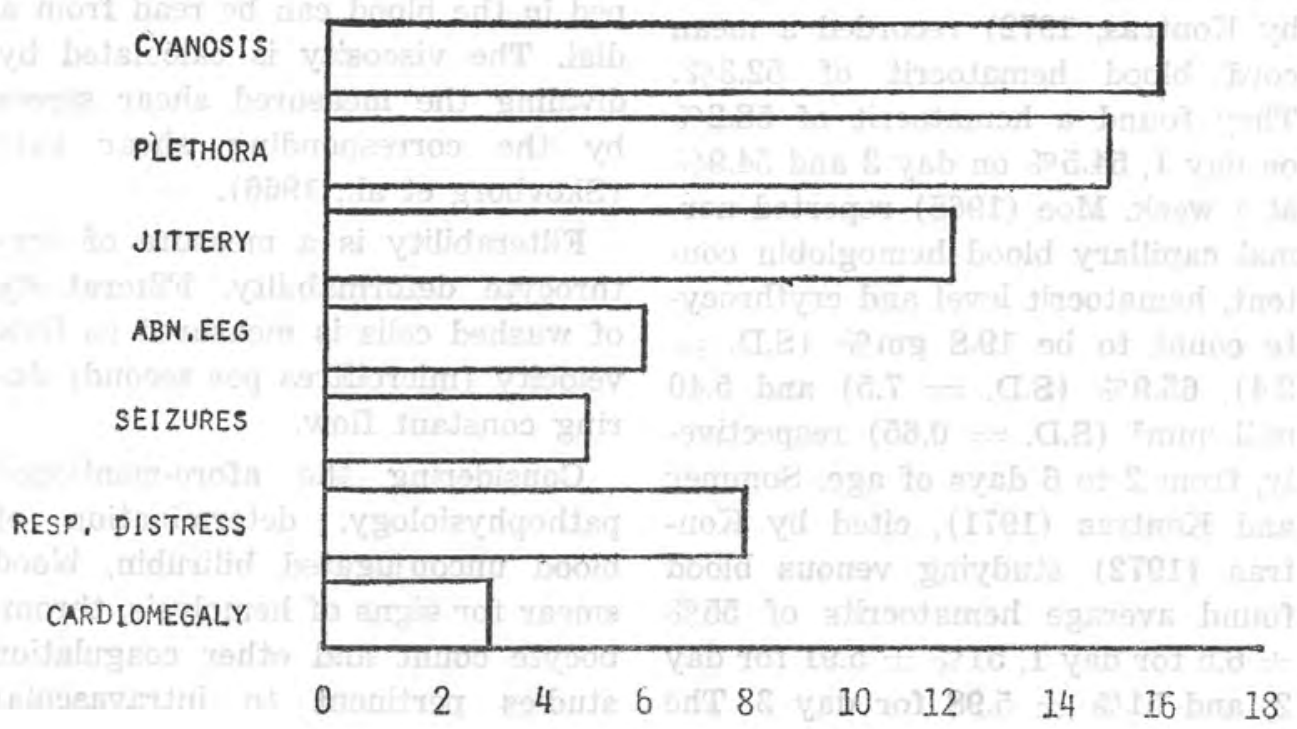


coagulation should be done. Blood sugar, calcium and magnesium estimations should be done in the routine testing of the infant with cerebral signs.

To determine the cause of polycythemia, estimation of fetal hemoglobin, Beta 2 A-globulin and differential red cell agglutinations are mandatory.

\section{Prognosis}

Most of the symptomatic cases reported in the literature improved dramatically after appropriate therapy. A lot of other cases were reported even with symptoms subsiding spontaneously (Gatti et al., 1966; Mackintosh and Walker, 1973). A long-term evaluation, however, of the symptomatic and asymptomatic cases is still necessary in view of subsequent neurologic impairment. It is noteworthy that insufficiency of cerebral perfusion may occur even in the absence of symptoms (Kontras, 1972).Cases with residual neurologic deficits reported in the literature are still too few. Of Wood's 2 patients who had convulsions associated with cyanosis and plethora, one developed grand mal seizures with episodes of transient blindness 7 years later (Gatti et al, 1966). Of the 3 patients in Gatti's 10 symptomatic study cases with myoclonic seizures, 2 had neurologic sequelae viz hemiparesis and myoclonic seizures at follow up. Gross et al. (1973) found motor and/or mental retardation on subse- quent examination in 4 of his 10 symptomatic cases. Danks and Stevens (1964) found a slight internal strabismus developed in his patient at a later date.

\section{Treatment}

There is little agreement as to indications for treatment. Usually no treatment is necessary (Wood, 1959) and spontaneous improvement generally occurs (Gatti et al,, 1966) but if there are symptoms of lethargy, anorexia, respiratory distress or convulsions, then treatment is indicated (Wood, 1959; Danks and Stevens, 1964; Kontras, 1972).

Hyperviscosity of blood is multifactorial and effective clinical management of the many circulatory and hematologic conditions represented by these syndromes will be based upon an understanding of mechanisms that create the hyperviscous state (Wells, 1970).

For a rational therapeutic approach it is important to know whether or not the polycythemic neonate is hypervollemic.

In normovolemic polycythemia there is a decreased cardiac output and partial exchange transfusion using $30 \mathrm{ml} / \mathrm{kg}$ body weight plasma or plasma expander may produce gratifying results when the venous hematocrit is 65 to $70 \%$ (Mackintosh and Walker, 1973). The capillary hematocrit is usually $5-6 \%$ higher. Exchange transfusion with plasma 
or plasma expander has the advantage over exchange transfusion with saline or glucose saline because it eliminates the risk of hypovolemia.

In hypervolemic polycythemia the$r e$ is an increased cardiac output and those infants suffering from cardiac failure may benefit from a phlebotomy of 10 per cent blood volume '(Kontras, 1972) to bring the blood volume to a nearly normal value. Phlebotomy could be fatal to a cyanotic baby who has normovolemic polycythemia by decreasing an already very low cardiac output (Fouron and Hebert, 1973).

Administration of oxygen serves to reduce pulmonary vascular resistance (Gersony, 1973) and decreases the red cell volume and hematocrit value by depressing bone marrow activity thereby lowering the viscosity of the blood (Gatti et al., 1966).

Anticonvulsant drugs in presence of neurologic seizures and digitalis in presence of cardiac failure may be considered with regard to therapy.

\section{Summary and conclusions}

Syndrome of hyperviscosity in the neonate is a well-established condition. Polycythemia is defined as a venous hematocrit of $65 \%$ or greater. Polycythemic hyperviscosity is the most common and may be due to intrauterine anoxia, small for gestational age and dysmaturity, chromosomal abnormalities, maternofetal and twin-to-twin transfusions, and delayed cord clamping. Because of a variety of reasons, the newborn is particularly susceptible to developing hyperviscosity. Clinical manifestations are not always present and are pertinent to circulatory overload or sludging of blood flow. Early diagnosis and prompt treatment are highly desirable as the condition is life-threatening or may bring about sequelae whereas treatment is promising. A distinction between normovolemic and hypervolemic polycythemia should be attempted in regard to treatment.

\section{REFERENCES}

1. BAUM, R.S. : Viscous forces in neonatal polycythemia. In Proceedings of the Society for Pediatric Research. Atlantic City. J. Pediatr. $69: 975$ (1966).

2. BAUM, R.S. : Hyperviscous Blood and Perinatal Pathology. Abstract of a paper presented at the Meeting of the American Pediatric Society, Atlantic City, April 26 to 29, 1967. (eited by Schaffer and Avery, 1971).
3. BUCKELS, L.J., and USHER, R. : Cardiopulimonary effects of placental transfusion. J. Pediatr, $67: 239$ (1965).

4. CHAPTAL, J., JEAN, R., IZARN, P., CAMPO, C. and MENARD P. : La polyglobulie pathologique neonatale. Pediatrie 13: 515 (1958) (cited by Mackintosh and Walker, 1973).

5. CHRISPIN, A.R, and DARKE, C.S. Papiloedema and polyeythaemia. Brit. Med $J_{, k} 5283$ : 989 (1962). 
6. COEN, R.W. and SUTHERLAND, I.M. : Placental vascular communications between twin fetuses. A simplified technirue for demonstration. Amer. J. Dis. Child. 120: 332 (1970).

7. DANKS, D.M., and STEVENS, L.H.: Neonatal respiratory distress associated with a high haematocrit reading. Lancet ii : 499 (1964),

8. FAHEY, J.L., BARTH, W.F., and SOLOMON, A. : Serum hyperviscosity syndrome, J. amer. med. Ass. 192 : 464 (1965).

9. FOURON, J.C., and HEBERT, F. : The circulatory effects of hematocrit variations in normovolemic newborn lambs. J. Pediatr. 82; 995 (1973),

10. GATTI, R.A., MUSTER, A.J., COLE, R.B., and PAUL, M.H. : Neonata! polycythemia with transient cyanosis and cardiorespiratory abnormalities. J. Pedialt. 69: 1063 (1966).

11. GERSONY, W.M. : Persistence of the fetal circulation: A commentary. J. Pediatr, 82: 1103 (1973).

12. GREGG, D.E., and WIGGERS, C.L., The circulatory effects of acute experimental hypervolemia. Amer. J Physiol. 104 : 423 (1933). (cited by Murray J.F. et al., 1963).

13. GROOS, G.P., HATHAWAY, W.E., and McGAUGHEY, H.R.: Hyperviseosity in the neonate. J. Pediatr. 82 ; 1004 (1973).

14. GUEST, G.M., and BROWN, E.W. : Erythrocytes and hemoglobin of the blood in infancy and childhood: factors in variability, statistical studies. Amer. J. Dis. Child, $93: 486$ (1957), (cited by Kontras, S.B., 1972).

15. HUMBERT, J.R., ABELSON, H., HATHAWAY, W.E., and BATTAGLIA, F.C. : Polycythemia in small for ges- tational age infants. J. Pediatr. 75 ; 812 (1969).

16. KONTRAS, S.B., BODENBENDER, J.G., CRAENEN, J., and HOSIER, D.M. : Hyperviscosity in congenital heart disease. J. Pediatr. $76: 214$ (1970)

17. KONTRAS, S.B.: Polycythemia and hyperviscosity syndromes in infants and children. Pediatr. clin. N. Amer., 19: 919 (1972).

13. LAPPALAINEN, I., and KOUVALAINEN, K, : High hematocrits in new. borns with Down's syndrome, a hitherto undescribed finding. Clin. Pediatr 11 : $472(1972)$.

19. LEES, M.H. : Cyanosis of the new born infants. J. Pediatr. $77: 484$ (1970).

20. MACKINTOSH, T.F., and WALKER, C.H.M. : Blood viscosity in the newborn. Arch. Dis, Child. 48 : 547 (1973).

21. MEADOWS, S.P. : Papiloedema associated with chronic bronchitis, emphysema and polycythemia. Proc. Roy. Soc. Med. 40 : 555 (1947).

22. MICHAEL, A.E., and MAUER, A.M.: Maternal-fetal transfusion as a cause of plethora in the neonatal period. Pediatries 28: 458 (1961).

23. MOE, P.J. : Normal red blood pleture during the first three years of life. Acta Pediatr. Scand, 54: 69 (1965).

24. MURRAY, J.F.: Classification of polycythemia disorders. With comments on the diagnostic value of arteria! blood oxygen analysis. Ann. Intern. Med. $64: 892$ (1966) (cited by Kontras, S.B., 1972).

25. MURRAY, J.F., GOLD, P, and JOHNSON, B.L. Jr. : The circulatory effects of hematocrit variations in normovolemic and hypervolemic dogs. J, Clin, Invest. 42 : 1150 (1963). 
26. NAEYE, R.L.: Human intrauterine parabiotic syndrome and its complications. New Engl. J. Med. 268 : 804 (1963)

27. O'CONNOR, J.F., SHAPIRO, J.H. and INGALL, D. : Erythrocythemia as a cause of respiratory distress in the newborn: radiologic findings. Radiology $90: 333$ (1968).

28. OH, W., and LIND, J.: Venous and capillary hematocrit in newborn infants and placental transfusion. Acta Paediatr. Scand. 55 : 38 (1966).

29. OSKI, F.A. and NAIMAN, J.L. : Hematologic problems in the newborn. p.6 (Saunders, Philadelphia and London, 1966).

30. PAPAGEORGIOU, A. and STERN, L: Polycythemia and gangrene of an extremity in a newborn infant. J. Pediatr. 81: 985 (1972).

31. PHILIP, A.G.S., YEE, A.B., ROSY, M., SURTI, N., TSAMTSOURIS, A., and INGALL, D: Placental transfusion as an intra-uterine phenomenon in deliveries complicated by foetal đistress. Brit. Med. J. 2 : 11 (1969). (cited by Mackintosh, T.F., and Wal. ker, C.H.M., 1973).

32. REPLOGLE, R.L., and MERRILL, E.W. : Experimental polycythemia and hemodilution. J. Thorac. Cardiovasc. Surg. $60: 582$ (1970).

33. ROTHSTEIN,. T : Bilateral, central retinal vein closure as the initial manifestation of polycythemia. Am. J. Ophthalmol. $74: 256$ (1972).

34. SCHAFFER, A.J., and AVERY, M.E. : Diseases of the newborn, 3rd. ed. p. 494
(Saunders, Philadelphia-London-Toronto, 1971).

35. SINGH, M. and SETHI, A.S.: The intrauterine twinto-twin transfusion syndrome. Indian Pediatr.6: 635 (1969).

36. SKOVBORG, F., NIELSEN, Aa, V., SCHLICHTKRULL, J., and DITZEL, $\mathrm{J}$ : Blood-viscosity in diabetic patients. Lancet i : 129 (1966).

37. SOMMER, A., and KONTRAS, S.B. : Studies of blood viscosity in the normal newborn. Biol. Neon. 17: 616 1967) (cited by Kontras, S.B., 1972).

38. SUKADI, A, and ALISJAHBANA, A.: Neonatal polycythemia (case report), Pediatr. Indones. 14 : 63 (1974).

39. USHER, R., SHEPARD, M, and LIND, $\mathrm{J}$. : The blood volume of the newborn infant and placental transfusion, Acta Paediatr. 52 : 497 (1963).

10. WALKER, J., and TURNBULL, E.P.N. : Haemoglobin and red cells in the human foetus. Lancet ii : 312 (1953).

41. WEINBERGER, M.M., and OLEINICK, A. : Congenital marrow dysfunction in Down's syndrome. J. Pediatr. 77: 273 (1970).

42. WELLS, R.E., and MERRILL, E.W.: The variability of blood viscosity. Am. J. Physiol. 31 ; 505 (1961).

43. WELLS, R. : Syndromes of hyperviscosity, New Engl. J. Med. 283 : 183 (1970).

14. WOOD, J.L. : Plethora in the newborn infant associated with cyanosis and convulsions. J. Pediatr, 54 : 143 1950). 